\title{
Entrevista com Leonardo Tonus
}

Joelma Santana Siqueira (Universidade Federal de Viçosa).

Vivaldo Andrade dos Santos (Georgetown University).

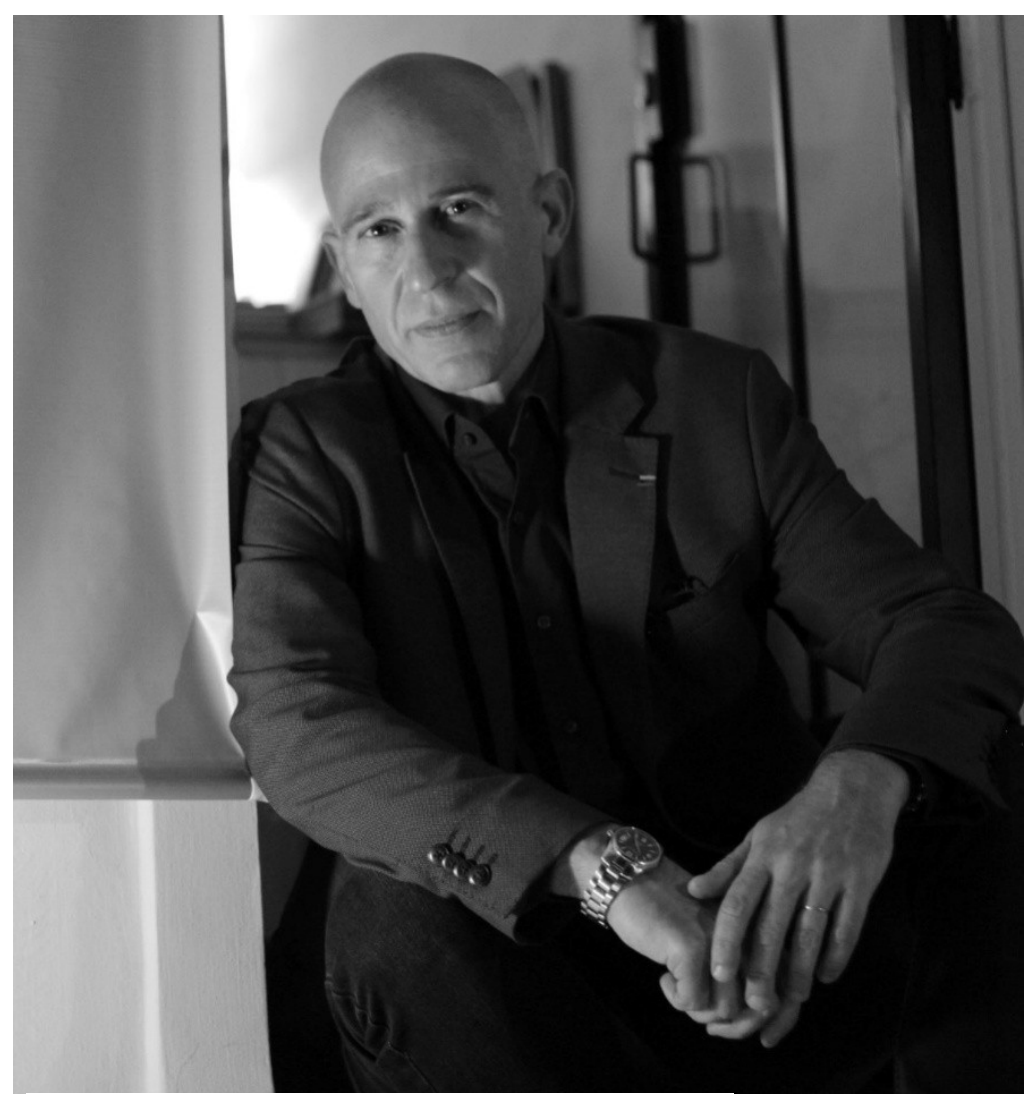

Fonte: Arquivo do autor. Créditos: André Argolo.

Leonardo Tonus é professor de Literatura Brasileira na Sorbonne Université (França). Em 2014 foi condecorado Chevalier das Palmas Acadêmicas pelo Ministério de Educação francês e, em 2015, Chevalier das Artes e das Letras pelo Ministério da Cultura francês. Curador do Salon du Livre de Paris de 2015 e da exposição "Oswald de Andrade: passeur anthropophage", no Centre Georges Pompidou (França, 2016). É idealizador e organizador do festival Printemps Littéraire Brésilien. Publicou diversos artigos acadêmicos sobre autores

Gláuks: Revista de Letras e Artes - jul/dez 2020 - v. 20, n. 2 
brasileiros contemporâneos e coordenou, entre outros, a publicação de Samuel Rawet: ensaios reunidos (José Olimpio, 2008), do volume 4 da Chiricú Journal: Latina/o Literatures, Arts, and Cultures (Indiana University Press, 2020) e das antologias La littérature brésilienne contemporaine - spécial Salon du Livre de Paris 2015 (Revista Pessoa, 2015), Olhar Paris (Editora Nós, 2016), Escrever Berlim (Editora Nós, 2017) e Min al mahjar ila al watan - Da Terra de Migração Para a Terra Natal (Revista Pessoa/ Abu Dhabi Departement of Culture and Tourism/Kalima, 2019). Vários de seus poemas foram publicados em antologias e revistas nacionais e internacionais. É autor de duas coletâneas de poesia: Agora Vai Ser Assim (Editora Nós, 2018) e Inquietações em tempos de insônia (Editora Nós, 2019).

1. Prezado Professor Leonardo Tonus, somos muito gratos a você por nos conceder essa entrevista para o presente dossiê da Gláuks dedicado ao tema "A literatura brasileira no exterior". Temos conhecimento de suas atividades como professor, pesquisador, escritor e tradutor e gostaríamos de saber como essas atividades contribuíram para a concepção do festival Printemps Littéraire Brésilien, criado por você em 2014.

O festival Printemps Littéraire Brésilien é um encontro anual idealizado para ampliar a formação de estudantes inscritos nos cursos de português em instituições de ensino no exterior. Contrariamente a outros festivais, ele inscreve-se numa perspectiva pedagógica que visa a potencializar experiências culturais em torno da língua portuguesa e de nossa cultura fora do Brasil.

O projeto decorre diretamente de minha experiência de docente e de pesquisador. Ele nasce dentro de minha sala de aula num contexto de crescente visibilidade e de promoção da literatura brasileira contemporânea no exterior.

Desde 2005 tinha por hábito receber escritores brasileiros e portugueses em minhas aulas de literatura na Sorbonne com o intuito de divulgar a cena literária lusófona mais recente. $\mathrm{O}$ aumento dessas visitas e a boa recepção por parte dos convidados fez com o

Gláuks: Revista de Letras e Artes - jul/dez 2020 - v. 20, n. 2 
festival tomasse o formato pedagógico que se manifesta pela implicação dos estudantes na organização anual dos encontros, na escolha dos autores e até na preparação e moderação das mesas.

Meu objetivo era fazer com que os estudantes descobrissem novos autores e participassem ativamente de um projeto comum, o que explica o fato do festival se inscrever inicialmente no espaço francês.

\section{Como o festival vem se constituindo ao longo desses anos, ou seja, como vem se estruturando em termos de espaços, alcance, participação de convidados, apoios etc?}

A escolha dos participantes do festival obedece a critérios rigorosos que levam em conta a diversidade das vozes de nossa cena literária atual: pluralidade geográfica, editorial, cultural e de gênero. Seu ponto frágil permanece, no entanto, nos apoios financeiros cada vez mais escassos e limitados. Até 2017, pudemos contar com um pequeno apoio de instituições consulares brasileiras, atualmente impossível após a mudança do governo e suas derivas ideológicas.

Em 2016, o projeto tornou-se associação sem fins lucrativos e um festival itinerante que, todos os anos, acontece em países europeus e no espaço norte-americano. Desde sua criação mais de 200 autores já participaram do evento que, em 2020, deveria se estender ao Brasil e à África. Infelizmente, por conta da epidemia do Coronavírus, tivemos de anular o conjunto dos encontros.

A $7^{\circ}$ edição do festival iria reunir, entre os meses de fevereriro e junho de 2020, mais de 70 escritores. O evento envolvia seis países e contava com a participação de mais de 30 instituições culturais, livrarias, bibliotecas, editoras, revistas, jornais literários e, é claro, estabelecimentos de ensino no exterior com centenas de estudantes diretamente envolvidos no projeto e nele trabalhando há quase um ano.

$\mathrm{Na}$ altura, não havia outra solução além do cancelamento das atividades. Foi uma decisão difícil mas responsável que me permitiu, no entanto, refletir profundamente sobre o

Gláuks: Revista de Letras e Artes - jul/dez 2020 - v. 20, n. 2 
funcionamento do campo literário brasileiro e a (in)visibilidadede de parte de seus agentes. Penso aqui nomeadamente na presença-ausência do público leitor, agente fulcral do campo literário mas dele muitas vezes esquecido quando não expurgado.

A este respeito podíamos nos lembrar do artigo polêmico que, em 2015, a professora Suzana Vargas publicava na seção de Cultura de $O$ Globo. Nele Suzana Vargas se indagava acerca dos objetivos das grandes festas e feiras literárias que se espalhavam pelo país e até pelo exterior. Segundo a crítica:

Eventos não levam ninguém a ler mais ou a comprar mais livros. Eventos literários sejam eles festas, feiras, bienais com maior ou menor projeção nacional, são fenômenos de marketing. Ou seja: eventualmente ouve-se falar num produto chamado livro, em seus autores, como quem anuncia uma nova marca de refrigerante. $O$ cidadão escuta através da mídia que livros são essenciais, que ler faz bem, acorre às feiras, as escolas se movimentam, as prefeituras distribuem o vale livro ou que nome tenha essa ajuda essencial dos órgãos envolvidos. Na verdade, feiras e eventos cumprem essa missão de popularizar o objeto livro, divulgar alguns nomes da produção literária nacional e internacional, mas são $[\ldots]$ eventuais ${ }^{1}$.

Obviamente é necessário ponderar as palavras da pesquisadora que, no entanto, permanecem atuais. Se ao longo dos anos a imagem do livro se desgastou, seriam os eventos literários capazes de recolocá-lo em pauta ? Ou não constituíriam estes mais um dispositivo do processo de espetacularização que cooptam os seus agentes em prol unicamente do mercado?

Em resposta ao artigo de Suzana Vargas, o gestor cultural Afonso Borges, criador do projeto "Sempre Um Papo" e curador do Festival Literário de Araxá (Fliaraxá), respondia em uma tribuna no jornal $O$ Globo, datada de abril de 2015:

Hoje vivemos o momento do autor. Não vale mais o livro, como objeto. Antigamente, o escritor passava anos escrevendo um livro e, por ele, era celebrado, e convidado. E vinha, cheio de graça, desfrutar de seu esforço solitário e criativo, metamorfoseado em páginas de um livro. Hoje, não. Hoje é o tempo do autor, da sua fala, da sua presença. O livro é sua extensão, seu... produto (palavra áspera, para os puritanos $)^{2}$.

1 VARGAS, Suzana. O que se festeja nas festas literárias? O Globo. Publicado em 04/04/2015. Disponível em: https://oglobo.globo.com/cultura/livros/o-que-se-festeja-nasfestas-literarias-15766932, acesso em 02 de novembro de 2020. 2 BORGES, Afonso. Feiras existem para estimular mercado e não para promover leitura, diz gestor. O Globo. Publicado em 11/04/2015. Disponivel em: https://oglobo.globo.com/cultura/livros/feiras-existem-para-estimular-mercado-nao-parapromover-leitura-diz-gestor-15839040, acesso em 02 de novembro de 2020.

Gláuks: Revista de Letras e Artes - jul/dez 2020 - v. 20, n. 2 
Peço licença a Afonso Borges pelo meu puritanismo (ou até, quem sabe, pelo meu profundo utopismo) que me leva ainda a crer na função do livro enquanto experiência subjetiva no sentido, já formulado por Umberto Eco, de criar comunidades. E foi justamente repensando este argumento que, sem arrependimentos, decidi pura e simplesmente anular este ano todas as atividades do Printemps Littéraire e me lançar numa aventura digital (Sacadas Literárias) centrada na experiência da leitura compartilhada.

A ideia surgiu quando me dei conta de que vários de meus estudantes (sobretudo os estudantes estrangeiros da pós-graduação em intercâmbio) iriam se encontrar em situação de isolamento sem poderem retornar aos seus países de origem e sem nenhum acesso a bibliotecas e outros espaços públicos. Junto com eles criei inicialmente grupos pelo WhatsApp para trocarmos informações práticas e conteúdo cultural. Com o passar dos dias propus-lhes que migrássemos para plataformas digitais afim de compartilhar com o máximo de pessoas as informações obtidas e a soliedariedade literária e afetiva surgida entre nós. Fico feliz (e honrado) ao observar a adesão a este projeto de amigas e amigos, de escritoras e de escritores ou de simples leitoras e leitores confinados como eu. Recebi e continuo a receber todos os dias vídeos de várias partes do mundo (Vietnã, Israel, Itália, Canadá, Portugal, Brasil) fortalecendo uma rede de leituras públicas até então pouco vistas e vivenciadas entre nós. $\mathrm{Na}$ esteira do Printemps Littéraire Brésilien, o Sacadas Literárias busca a dimensão afetiva do fazer literário que, em minha opinião, subjaz toda e qualquer atuação do e para o campo literário.

3. Eventos como Printemps Littéraire Brésilien podem ser vistos como exemplo do que políticas efetivas de internacionalização da Literatura Brasileira poderiam promover ou auxiliar?

Resido em Paris há mais de 30 anos e sou professor de Literatura Brasileira na Universidade da Sorbonne desde 2001. Ao longo dessas últimas décadas, assisti, não somente, à euforia em torno da promoção da língua portuguesa no ensino público francês, bem como ao

Gláuks: Revista de Letras e Artes - jul/dez 2020 - v. 20, n. 2 
seu declínio: o desaparecimento dos concursos para professores de português no secundário e o fechamento dos departamentos de estudos lusófonos nas universidades francesas. Estes contribuíram de maneira significativa à fragilização da presença do livro brasileiro no mercado editorial francês.

A aposta na internacionalização de nossa cultura realizada pelo governo brasileiro a partir da década de 1990 buscou inverter este quadro sombrio. Os benefícios, mesmo que irregulares e inconstantes, foram perceptíveis. Em 2012 o Brasil retornava ao Salão do Livro de Paris, o que levou a um aumento significativo de traduções ou reedições dos clássicos de nossa literatura e de jovens autores nacionais até 2015, quando o país foi convidado de honra do Salão. Masa polític a de internacionalização da literatura brasileira é um caso emblemático das contradições e das indefinições da história política brasileira. O que hoje sobrou deste grande esforço? Pouca coisa ou nada se levarmos em conta a ausência do país em quase todos os eventos internacionais ligados à literatura, bem como à sua imagem internacional que faz com que o número de traduções de nossa literatura hoje seja ínfimo.

\section{Quais são os desafios do Printemps Littéraire Brésilien daqui para frente?}

Como todos os eventos literários confrontados à crise pandêmica, o principal desafio do Printemps Littéraire Brésilien será, mais do que a sua sobrevivência, sua pertinência num mundo em que os laços sociais foram profundamente afetados. Mas esta história só poderemos contá-la no próximo ano. 